\title{
Prevalence of underweight, stunting and wasting in under five years old children based in the WHO-2006 and CDC-2000 growth standard on Kintamani, Bangli
}

\author{
I Gusti Lanang Sidiartha
}

\begin{abstract}
Background Healthy children will have normal growth according to their age and gender. To assess and monitor the growth of children, a growth standard is needed. The WHO and CDC released a new growth standard to replace the 1977 NCHS growth standard in April 2006 and May 2000 respectively.

Objective To obtain the prevalence of underweight, stunting and wasting in less than five years old children based on the WHO-2006 and CDC-2000 growth standard and compared the results.

Methods A cross-sectional study was conducted in Songan Village, District of Kintamani, Bangli on December 2006. Healthy children aged 0.59 months who visited the study site were enrolled. Anthropometric data including weight and length/height were obtained using standard anthropometrics procedures by trained doctor assistants. Nutritional status was determined by calculating Z-score values (cutoff point -2SD) weight-for-age (underweight), length/height-for-age (stunting) and weight-for-length/height (wasting) using WHO-2006 and CDC-2000 growth standard. McNemar test was done to compare both results and $\mathrm{P}<0.05$ was considered as a statistically significant. Results There were 264 children, consisted of 139 (52.7\%) male and $125(47.3 \%)$ female. The prevalence of underweight, stunting and wasting based on WHO 2006 was 20.5\%, 20.1\% and 45.1\% respectively and based on CDC 2000 was $26.5 \%, 12.1 \%$ and $52.3 \%$. The difference was statistically significant $(\mathrm{P}<0.0001)$.

Conclusion The prevalence of underweight and wasting in children less than five years old based on the WHO-2006 was lower compared to that based on CDC-2000, while the prevalence of stunting was higher. [Paediatr Indones 2008;48:76-80].
\end{abstract}

Keywords: underweight, stunting, wasting, WHO2006, CDC-2000

76 - Paediatr Indones, Vol. 48, No. 2, March 2008

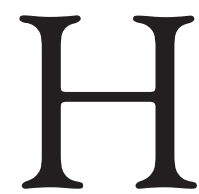

ealthy children will have normal growth according to their age and gender. To assess and monitor the growth of a child, a normal growth standard is needed. The growth standard from the National Center for Health Statistics (NCHS) that was published in 1977 is one of the growth standards that had been used in more than 100 countries in the world. ${ }^{1}$ Recently, the NCHS growth standard can not be used to assess the growth of children, particularly who have exclusive breastfeeding according to $\mathrm{WHO}$ recommendation. ${ }^{2}$ WHO recommends making a new multi-ethnic growth standard that can be used to assess the growth of exclusive breastfed babies. ${ }^{3}$

In May 2000, Center for Disease Control and Prevention (hereafter, CDC-2000) released a new growth standards, based on five nationally representative surveys conducted between 1963 and 1994.4

Presented at The $3^{\text {rd }}$ Annual Scientific Meeting, Indonesian Pediatric Association, Yogyakarta, Indonesia, May 6-9, 2007.

From the Department of Child Health, Medical School, University of Udayana, Sanglah Hospital, Denpasar, Indonesia.

Reprint requests to: I Gusti Lanang Sidiartha, MD, Department of Child Health, Medical School, Udayana University, Sanglah Hospital, Jl. P. Nias, Denpasar, Indonesia. Tel./Fax. 62-361-244038. E-mail: lanangsidiartha @yahoo.com 
On the other hand, in April 2006, WHO released new growth standards for assessing the growth of children from birth to five years of age (hereafter, WHO-2006). ${ }^{5-7}$ Both the CDC-2000 and WHO2006 were developed to replace the 1977 NCHS growth standard.

The aim of the study was to obtain the prevalence of underweight, stunting and wasting in less than five years old children, based on the WHO. 2006 and CDC-2000 growth standard.

\section{Methods}

A cross-sectional study was conducted in Songan Village, District of Kintamani-Bangli on December 2006. Children aged 0-59 months, singleton, term birth weight 2500 grams or more were included. Children known to suffer from severe congenital disorders, chronic diseases and/or acute severe diseases that could alter the physical growth were excluded from this study. Parents of the children signed the informed consent.

Sample size was calculated based on descriptive proportion formula with $40 \%$ prior prevalence of malnutrition and $10 \%$ precision with $95 \%$ level of confidence interval. The minimal sample size needed was 230 subjects. The basic characteristics of children included name, birth date, gender, health status, body weight and body length or height were obtained through an interview with the parents and a direct physical examination on the children.

Anthropometric data including body weight and length were obtained from all subjects using standard anthropometric procedures by trained doctor assistants. Nutritional status was determined by calculating Zscore values (cut-off point -2SD) weight-for-age (underweight), length/height-for-age (stunting) and weight-for-length/height (wasting) using WHO-2006 and CDC-2000 growth standard.

\section{WHO-2006}

The WHO-2006 were created based on the WHO Multicentre Growth Reference Study (MGRS) in Brazil, Ghana, India, Norway, Oman, and the United States between 1997 and 2003. The study combined a longitudinal follow-up from birth to 24 months of age with a cross-sectional component of children aged 18-71 months. The inclusion criteria were: no known health or environmental constraints to growth, mothers willing to follow MGRS feeding recommendations (exclussive or predominant breast-feeding for at least four months, introduction of complementary foods by six months of age, and continued breastfeeding to at least 12 months of age), no maternal smoking before and after delivery, single term birth, and absence of significant morbidity. Data were pooled for constructing the growth standards of children aged $0-60$ months. ${ }^{8}$

\section{CDC-2000}

In the United States of America, the CDC-2000 was created based on national data collected in a series of five surveys between 1963 and 1994. All surveys included the Fels Longitudinal Study data set, NHANES II (1976-1980), NHANES III (1988-1994), the United States Vital Statistics birth certificates, and the clinics of the Pediatric Nutrition Surveillance System (PedNSS). The CDC-2000 was based on relatively few infants who were breast-fed for more than a few months. The advantage of CDC-2000 is that CDC 2000 could be used for children from birth to 20 years old. ${ }^{8}$

Data were processed by SPSS version 11.5 for windows and analyzed using McNemar test. P value $<0.05$ was considered as a statistically significant difference. The study was approved by the Committee of Medical Research Ethics, Medical School, University of Udayana.

\section{Results}

Two hundreds and sixty-four children are included in this study, consisted of 139 (52.7\%) male and $125(47.3 \%)$ female. Age distribution is depicted in Table 1.

Table 2 shows that the prevalence of underweight, stunting and wasting for all subjects based on the WHO-2006 were $20.5 \%, 20.1 \%, 45.1 \%$ respectively and based on CDC 2000 was $26.5 \%, 12.1 \%$, $52.3 \%$, respectively. Both the difference was statistically significant $(\mathrm{P}<0.0001)$. According to gender of the children the prevalence difference was 
I Gusti Lanang Sidiartha: Underweight, stunting and wasting in under five years old children

Table 1. Characteristics of study subjects

\begin{tabular}{lcc}
\hline Characteristics & $\mathrm{n}$ & $\%$ \\
\hline $\begin{array}{l}\text { Gender } \\
\text { Male }\end{array}$ & 139 & \\
$\quad$ Female & 125 & 52.7 \\
Age group & & 47.3 \\
0-6 mo & 29 & \\
$7-12$ mo & 49 & 11.0 \\
$13-24$ mo & 58 & 18.6 \\
$25-36$ mo & 55 & 22.0 \\
37-48 mo & 56 & 20.8 \\
$49-59$ mo & 17 & 21.2 \\
&
\end{tabular}

Table 2 Prevalence of underweight, stunting and wasting based on the WHO-2006 and CDC-2000

\begin{tabular}{cccc}
\hline & $\begin{array}{c}\text { WHO-2006 } \\
(\%)\end{array}$ & $\begin{array}{c}\text { CDC-2000 } \\
(\%)\end{array}$ & $\mathrm{P}$ \\
\hline All subjects, $\mathrm{n}=264$ & & & \\
Underweight & 20.5 & 26.5 & 0.0001 \\
Stunting & 20.1 & 12.1 & 0.0001 \\
Wasting & 45.1 & 52.3 & 0.0001 \\
Male, n=139 & & & \\
Underweight & 20.1 & 28.1 & 0.007 \\
Stunting & 24.5 & 16.5 & 0.001 \\
Wasting & 43.9 & 49.6 & 0.021 \\
Female, n=125 & & & \\
Underweight & 20.8 & 24.8 & 0.012 \\
$\quad$ Stunting & 15.2 & 7.2 & 0.002 \\
Wasting & 46.4 & 55.2 & 0.001 \\
\hline
\end{tabular}

statistically significant ( $\mathrm{P}<0.05$ for all items).

Figure 1 shows the prevalence of underweight based on the WHO-2006 and CDC-2000 according to age groups. The main differences in the prevalence of underweight occurred during infancy. Based on the WHO 2006 the prevalence of underweight was higher during the first six months of life and lower thereafter throughout childhood. The peak of underweight occurred in the aged group of 25-36 months.
Figure 2 shows the prevalence of stunting based on the WHO-2006 and CDC-2000 according to age groups. Based on the WHO 2006, for all age groups, the prevalence of stunting was higher compared to that based on CDC-2000. The peak of stunting occurred in aged group of 13-24 months.

Figure 3 shows the prevalence of wasting based on the WHO-2006 and CDC-2000 according to age groups. The prevalence of wasting based on WHO 2006 was lower compared with that based onCDC2000 for all age groups. The peak of wasting occurred in the aged group of 25-36 months.

\section{Discussion}

In this study the prevalence of underweight based on the WHO-2006 was lower than that based on CDC2000 for all of the subjects and according to the gender as well. But there was an exception at the age of less than six months where the prevalence of underweight based on the WHO 2006 was higher. It means that in general, the WHO-2006 subjects seem to be lighter than CDC-2000 except during the first six months of life. Differences in those of feeding types are likely to contribute to the difference growth patterns in weightfor-age during the first six months of life. ${ }^{8}$ Whereas the WHO-2006 are based solely on breast-fed infants, while the CDC-2000 are based on relatively few infants who were breast-fed for more than a few months. ${ }^{2,9}$ Breast-fed infants particularly exclussive breast-fed for at least four or six months will have a rapid growth. WHO-2006 growth standard succeded to capture the rapid growth of infants in early life,

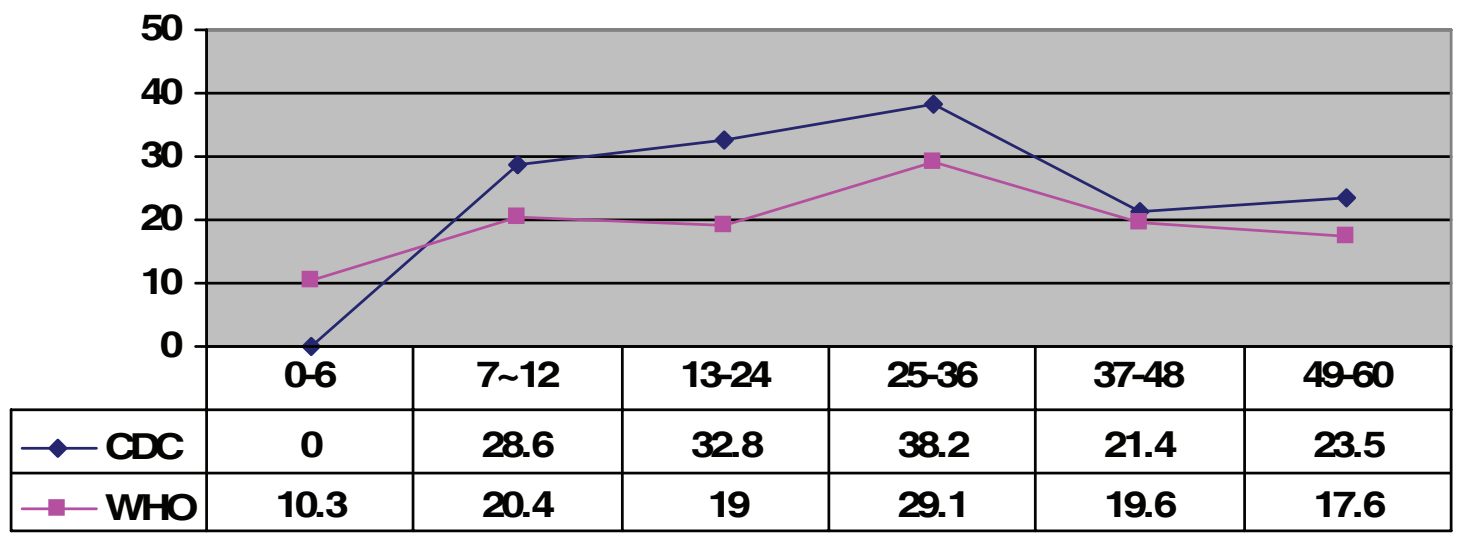

Figure 1. Prevalence of underweight based on the WHO-2006 and CDC-2000 
I Gusti Lanang Sidiartha: Underweight, stunting and wasting in under five years old children

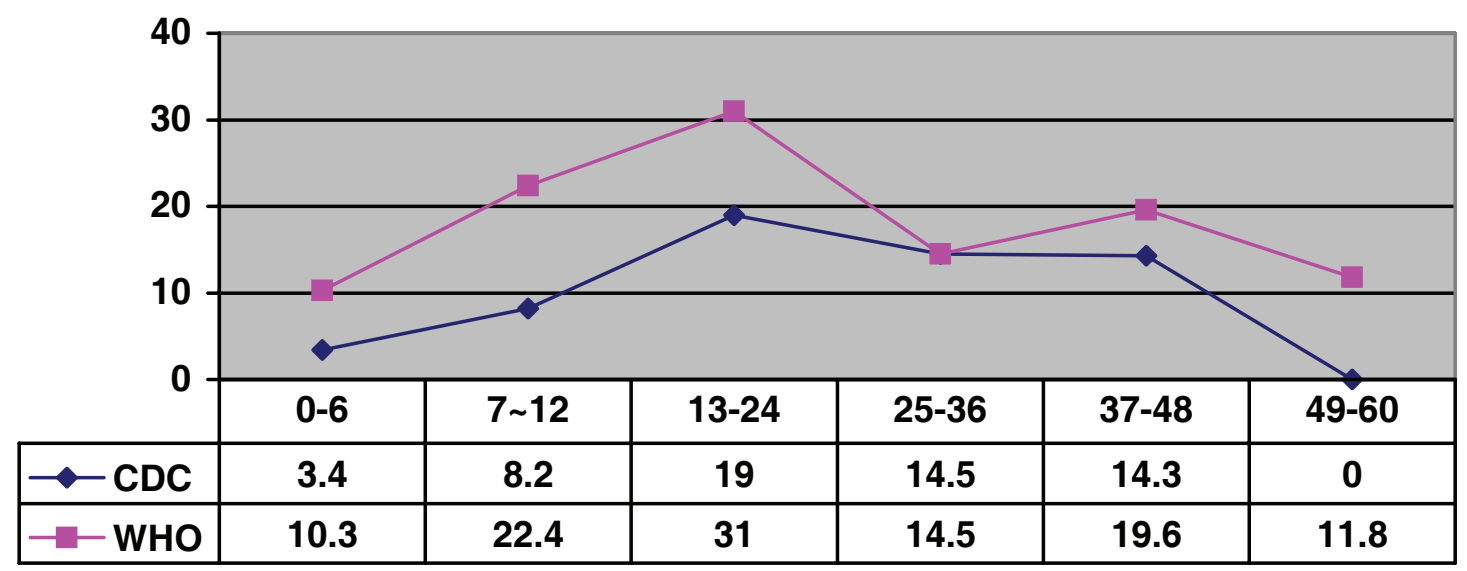

Figure 2. Prevalence of stunting based on the WHO-2006 and CDC-2000.

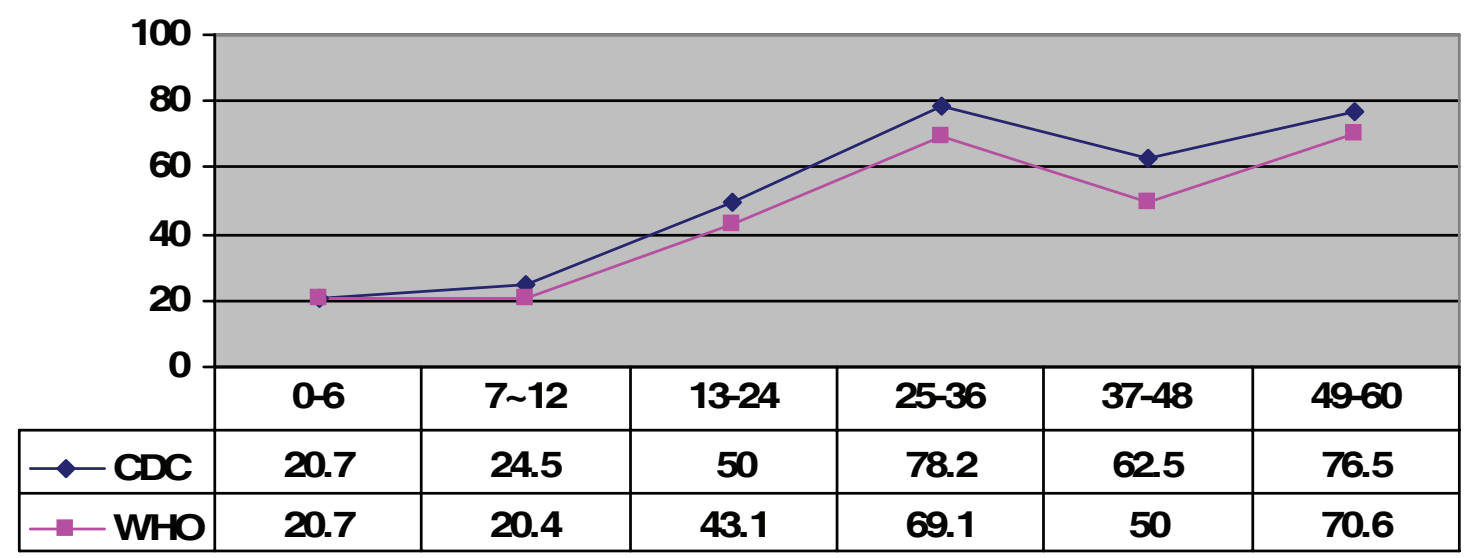

Figure 3. Prevalence of wasting based on the WHO-2006 and CDC-2000.

caused by the fact that $\mathrm{WHO}-2006$ use the longitudinal follow-up design from birth to 24 months and bigger sample size. ${ }^{10}$ In contrast, the cross-sectional design was used in the CDC-2000 so that the CDC2000 subjects probably failed to capture the rapid weight gain in early infancy. ${ }^{8}$

The prevalence of stunting based on the $\mathrm{WHO}$ 2006 was higher than that based on CDC-2000 for all of the subjects and according to the gender and age group as well. This finding showed that children in the WHO-2006 growth standard group were in average, taller than those in the CDC-2000. The tighter variability of the WHO-2006 due to the prescriptive approach and standardization of the measurements probably played a role in this finding. ${ }^{8}$ In contrast, the use of multiple datasets in the construction of the CDC-2000 [Vital Statistics birth registry data from two states, data from PedNSS up to 4.9 months, and data from NHANES II (from six months) and NHANES III (from three months)] with no standardization of measurements across them was prone to have artificially inflated the variability. ${ }^{4}$

The U.S. children who were involved in the construction of the CDC-2000 were generally heavier than those included in the WHO-2006 sample. ${ }^{8}$ Consequently, the prevalence of wasting based on the WHO-2006 is lower than that based on CDC-2000. Similar with this study, the prevalence of wasting based on the WHO-2006 was lower than that based on CDC-2000 for all of the subjects and according to the gender and age group as well.

In conclusion, the prevalence of underweight and wasting in children less than five years old based on the WHO-2006 was lower than that based on the CDC-2000, while the prevalence of stunting was 
I Gusti Lanang Sidiartha: Underweight, stunting and wasting in under five years old children

higher. In exception for underweight in the first six months of life, which the prevalence was higher based on the WHO-2006.

\section{References}

1. De Onis M, Wijnhoven TMA, Onyango AW. Worldwide practices in child growth monitoring. J Pediatr 2004;144:461-5.

2. World Health Organization Working Group on Infant Growth. An evaluation of infant growth: the use and interpretation of anthropometry in infants. Bull World Health Org 1995;73:165-74.

3. De Onis M, Habicht JP. Anthropometric reference data for international use: recommendations from a World Health Organization Expert Committee. Am J Clin Nutr 1996; 64:650-8.

4. Kuczmarski RJ, Ogden CL, Guo SS, Grummer-Strawn LM, Flegal KM, Mei Z, et al. 2000 CDC growth charts for the United States: methods and development. Vital Health Stat 2002;246:1-190.
5. De Onis M, Garza C. Time for a New Growth Reference. Pediatrics 1997:100:1-2.

6. Garza C, de Onis M. A new international growth reference for young children. Am J Clin Nutr 1999;70:S169-72.

7. World Health Organization Multicentre Growth Reference Study Group. World health Organization Child Growth Standards based on length/height, weight and age. Acta Paediatr 2006;450:S76-85.

8. De Onis M, Garza C, Onyango AW, Borghi E. Comparison of the WHO Child Growth Standards and the CDC 2000 Growth Charts. J Nutr 2007;137:144-8

9. Hediger ML, Overpeck MD, Ruan WJ, Troendle JF. Early infant feeding and growth status of US born infants and children aged 4-17 months: analyses from the third National Health and Nutrition Examination Survey, 1988-1994. Am J Clin Nutr 2000;72:159-67.

10. De Onis M, Onyango AW, Van den Broeck J, Chumlea WC, Martorell R, WHO Multicentre Growth Reference Study Group. Measurement and standardization protocols for anthropometry used in the construction of a new international growth reference. Food Nutr Bull 2004;25:S27-36. 